\title{
EFFECT OF PALM OLEIN ADDITION ON THE QUALITY CHARACTERISTICS OF SUNFLOWER OIL DURING DEEP FAT FRYING
}

\author{
M. Abbas Ali ${ }^{a *}, Z_{\text {. Bamalli Nouruddeen }}^{\mathrm{a}}$, I. Idayu Muhamad ${ }^{\mathrm{a}}$, R. Abd Latip ${ }^{\mathrm{b}}$ and \\ N. Hidayu Othman ${ }^{b}$

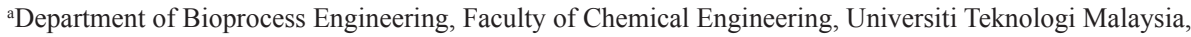 \\ UTM Skudai, 81310 Johor. Malaysia

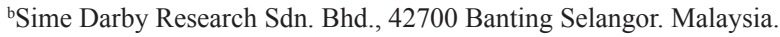

(Received: 12 November 2012; accepted: 20 January 2013)

\begin{abstract}
The aim of the present study was to investigate the effects of palm olein (PO) addition on the quality characteristics of sunflower oil (SFO) during frying of potato pieces. The blends were prepared in the volume ratios of 20:80 (PO:SFO, PSF1) and 40:60 (PO:SFO, PSF2). Refractive index, free fatty acid content, peroxide value, $p$-anisidine value, TOTOX, viscosity, specific extinction, polar compounds, food oil sensor value, colour, and polymer content of the oils all increased, whereas iodine value and $\mathrm{C}_{18: 2} / \mathrm{C}_{16: 0}$ ratio decreased as frying progressed. The percentage of linoleic and linolenic acids tended to decrease, whereas the percentages of palmitic and oleic acids increased. Based on the most oxidative stability criteria investigated, $\mathrm{PO}$ addition led to a slower deterioration of SFO at frying temperature. Blend PSF2 showed better frying performance compared to PSF1. However, higher amounts of free fatty acids and higher colour units were both detected in the blends compared to pure SFO at the end of frying. It appears that proper blending of highly unsaturated $\mathrm{SFO}$ with $\mathrm{PO}$ can result in oil blends that could meet nutritional needs with improved stability for domestic cooking and deep-frying.
\end{abstract}

Keywords: sunflower oil, palm olein, frying oil, polar compounds, fatty acids

Deep-fat frying is one of the most popular procedures for food preparation since it is rapid and develops desirable flavours and textures. However, using frying oils repeatedly can produce constituents that not only compromise food quality but also can promote the formation of compounds with adverse nutritional implications and potential hazards to human health. The quality and stability of frying fats are therefore of concern to food technologists, nutritionists, and consumers (SANiBAL \& MANCINI-Filho, 2004). The increased level of consumer awareness toward fat composition and its impact on human health can affect the selection of fats in the food industry. In addition, the choice of frying oil should also be made according to its performance in the frying process. Therefore, the use of more stable frying oils of comparatively low price would be desirable. To overcome the problem of poor stability of traditional soybean, sunflower, and rapeseed oils, ways of reducing the unstable polyunsaturated fatty acid (PUFA) content were sought. One way to improve the stability of these oils is by blending with oils of high oleic acid contents. Blending of vegetable oils/fats has emerged as an economical way of modifying the physicochemical characteristics of vegetable oils/fats beside the enhancement in the oxidative stability (CHU \& KUnG, 1998).

SFO is a rich source of vitamin $\mathrm{E}$ and contains alpha-tocopherol. It has a high level of linoleic acid (HuANG et al., 1981). High reactivity of this unsaturated fatty acid (USFA) is associated with oxidation, loss of nutritional value and quality (LABUZA, 1971). Moreover, its

\footnotetext{
* To whom correspondence should be addressed.

Phone: +6 07 55-36142; fax: +6 07 55-88166; e-mail: radwiya44@yahoo.com
} 
high cost restricts its usage on a major scale. PO is available in large amounts to a comparatively low price, while the availability of high oleic oils is limited at the moment, resulting in a higher price for the oil. Palm olein is being used increasingly in frying operations, and because of its inherent excellent frying properties, improves the frying quality of other vegetable oils when it is blended with them (ТЕAH, 1988). Therefore, this research was performed to study the effects of PO addition on the quality characteristics of SFO during frying by a combination of the most effective analytical and instrumental methods.

\section{Materials and methods}

\subsection{Materials}

Refined sunflower oil (Wintercorn Edible Products, Australia) and palm olein (Sime Darby Food and Beverages, Malaysia) were obtained from the local supermarket. Fresh potato was from the local food store. Potatoes were peeled, washed with water, and sliced into $6 \mathrm{~cm} \times 0.5$ $\mathrm{cm} \times 0.3 \mathrm{~cm}$ sizes and then dried. The vegetable oil blends were formulated by blending PO with SFO in the volume ratios of 20:80 (PO:SFO, PSF1) and 40:60 (PO:SFO, PSF2). The mixtures were stirred in a magnetic stirrer for $20 \mathrm{~min}$ for homogenization. Chemicals and solvents used were of analytical grade. $p$-Anisidine and silica gel were products of Merck (Darmstadt, Germany). Standards of fatty acid methyl esters were purchased from Supelco Chemical Co. (Bellefonte, PA, USA). All other chemicals and solvents were from J.T. Baker (Phillipsburg, USA) or RCI Labscan Ltd. (Pathumwan, Thailand) unless otherwise stated.

\subsection{Frying protocol and oil sampling}

Frying test was performed for SFO and its blends with PO. Several batches of potato pieces $(50 \mathrm{~g})$ were fried in a 2.51 domestic electric fryer (Philips HD-6159) at $185 \pm 5^{\circ} \mathrm{C}$ at intervals of $20 \mathrm{~min}$ up to $6 \mathrm{~h}$ per day for a total of 5 days. Two and a half litres of each oil sample to be tested were used for the frying. The fryer was switched on $15 \mathrm{~min}$ before beginning of frying each day to heat oil up to the desired frying temperature. Fresh oil was added after the collection of the sample to make up the oil to the initial level in the fryer (ENRíQUEZ-FERNÁNDEZ et al., 2011). The oil samples were collected and stored at $-16{ }^{\circ} \mathrm{C}$ for analyses each morning before replenishment. Initial physico-chemical analyses of the fresh samples (day 0) were also carried out.

\subsection{Oil analysis}

Fatty acid composition of the oil was determined by gas-liquid chromatography. Fatty acid methyl esters (FAME) were prepared according to PORIM (1995) test method p3.4 and analysed on an auto-system XL gas chromatograph (Perkin Elmer Incorporate, Massachusetts, USA) equipped with a fused silica capillary column $(60 \mathrm{~m} \times 0.25 \mathrm{~mm}$ i.d $\times 0.20 \mu \mathrm{m}$ film thickness, Perkin Elmer, USA) and a flame ionization detector. Nitrogen was used as carrier gas with a flow rate of $20 \mathrm{ml} \mathrm{min}{ }^{-1}$. Initial temperature was set to $100^{\circ} \mathrm{C}$, raised to $170{ }^{\circ} \mathrm{C}$ at $20{ }^{\circ} \mathrm{C} \mathrm{min}-1$, then programmed to $230{ }^{\circ} \mathrm{C}$ at $10^{\circ} \mathrm{C} \mathrm{min}^{-1}$, and finally heated to $250{ }^{\circ} \mathrm{C}$ at $30{ }^{\circ} \mathrm{C}$ $\mathrm{min}^{-1}$. The detector and injector temperatures were both maintained at $250{ }^{\circ} \mathrm{C}$. Methyl esters were quantified by comparing the retention times and peak area of the unknowns with known FAME standard mixtures. Refractive index, free fatty acid content, iodine value, and peroxide value were determined according to American Oil Chemists' Society official methods 
(A.O.C.S., 1987). Determination of specific extinctions at 233 and $269 \mathrm{~nm}\left(\mathrm{E}^{1 \%}{ }_{233}\right.$ and $\left.\mathrm{E}^{1 \%}{ }_{269}\right)$ and $p$-anisidine value of the samples were carried out by means of a Jenway 6305 spectrophotometer (Barloworld Scientific Ltd., UK) according to the PORIM (1995) test methods. Viscosity of the oils was measured by using a Brookfield DV-II+ viscometer (Brookfield Engineering Laboratories Inc., Middleboro, USA). Polymer compounds were analysed based on the method described by PELED and co-workers (1975). Total polar compounds were determined by means of mini column method (DoBARGANEs et al., 2000). Food oil sensor values were measured by using the food oil sensor instrument (CapSens 5000, C-Cit Ag, Wädenswil, Switzerland). A Lovibond Tintometer Model E (The Tintometer Ltd., Salisbury, England) was used to determine the colour according to PORIM (1995) test method.

\subsection{Statistical analysis}

All data were expressed as the mean and standard deviation (SD) and were subjected to one way analysis of variance (ANOVA). Mean values were compared at $\mathrm{P}<0.05$ significance level by Duncan's multiple range test using SPSS 11.5 software package.

\section{Results and discussion}

As shown in Table 1, linoleic was high in SFO (59.03\%) followed by oleic $(29.12 \%)$ and palmitic $(6.17 \%)$ acids. PO was characterized by a high content of oleic acid $(45.20 \%)$ followed by palmitic (38.44\%) and linoleic (11.59\%) acids. During frying the percentage of linoleic and linolenic acids tended to decrease, whereas the percentage of palmitic and oleic acids increased, probably due to PUFA degradation. Before frying, SFO and its blends contained trans $\mathrm{C}_{18: 2}(0.28$ to $0.36 \%)$. Trans $\mathrm{C}_{18: 1}$ was only found in $\mathrm{SFO}$ at the end of frying. In this work, total amount of trans fatty acid was considered instead of individual isomer. The blending of the SFO with the PO led to decreases in its ratio of $\mathrm{C}_{18: 2} / \mathrm{C}_{16: 0}$. The starting value of the $\mathrm{C}_{18: 2} / \mathrm{C}_{16: 0}$ ratio was lower in the blends than in $\mathrm{SFO}$ due to the addition of highly saturated PO. The ratio $\mathrm{C}_{18: 2} / \mathrm{C}_{16: 0}$ has been suggested as a valid indicator of the level of PUFA deterioration (NoRmAND et. al., 2001). The present study indicates that this ratio decreased in all oil samples during the frying process. The highest decreased amount from the initial was observed for the SFO (2.32 unit) followed by PSF1 (0.44 unit) with the least in PSF2 (0.26 unit). Present results revealed adding PO to SFO slowed down the rate of oxidative degradation of SFO.

Refractive index $(\mathrm{RI})$ values of frying oils were increased insignificantly $(\mathrm{P}<0.05)$ as the number of fryings performed in the oils increased (Table 2). R1 values of the blend PSF1 or PSF2 at corresponding frying days were significantly lower $(\mathrm{P}<0.05)$ compared to $\mathrm{SFO}$. However, adding PO to SFO decreased significantly the RI value of SFO. The free fatty acid (FFA) level of frying oils were significantly increased $(\mathrm{P}<0.05)$ with increasing frying time (Table 2). At the end of frying, the amount of FFA was found to be higher in PSF2 $(0.68 \%)$ followed by PSF1 $(0.61 \%)$ with the lowest in SFO $(0.59 \%)$. This result demonstrated that addition of PO to the SFO increased the FFA level of SFO; this might be due to high rate of increment of FFA in PO during frying compared to SFO. The significantly higher increment of FFA in PO compared to the sunflower/palm oil $(65: 35, \mathrm{v} / \mathrm{v})$ blend during frying was confirmed by DE MARCo and co-workers (2007). The highest FFA value detected in PSF2 at the end of frying is still far below the accepted limit of $2 \%$ (MatThaus, 2006). As shown in 


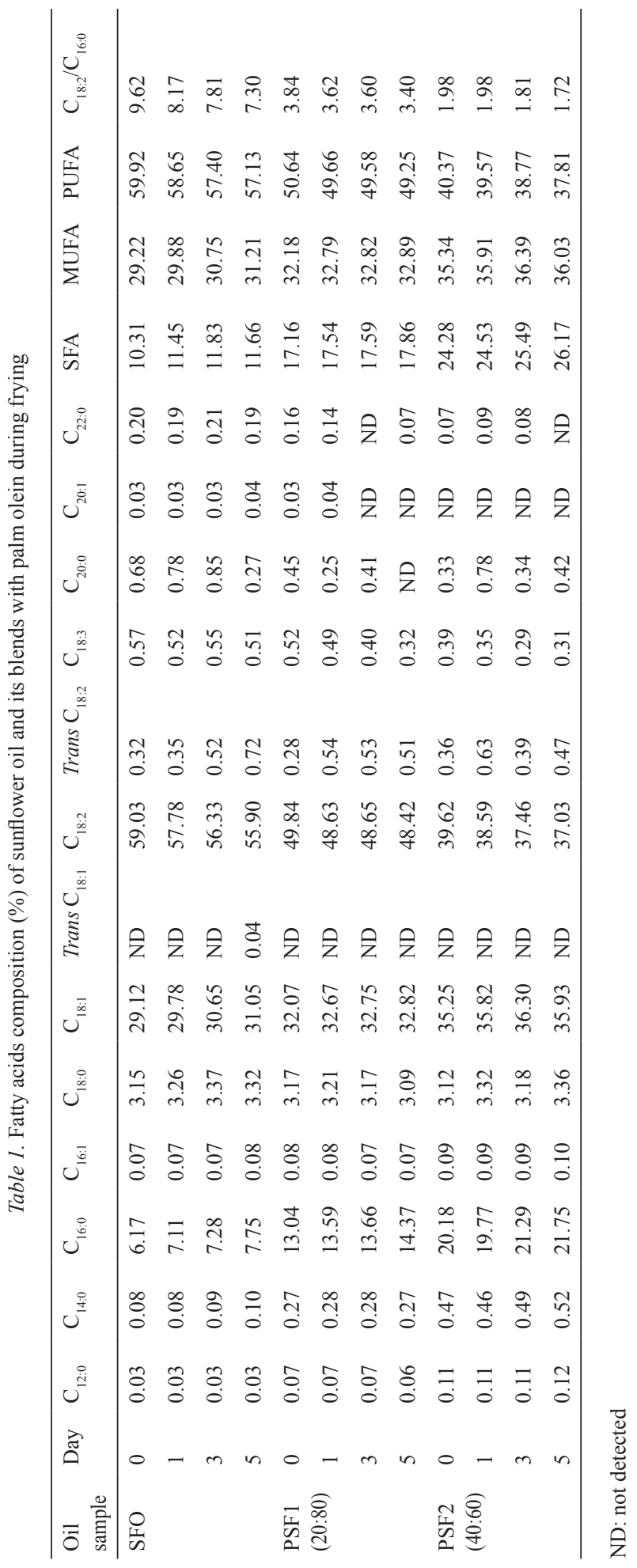


Table 2, the peroxide values (PV) during frying of all samples were increased up to the third day and then decreased until the end of the frying. Peak values were attained as follows: SFO (9.98), PSF1 (9.20), and PSF2 (9.00). The PV decreased in all oils after the peak was reached. SFO had the highest peak value compared to the blends. Addition of PO to SFO significantly decreased $(\mathrm{P}<0.05)$ the increment of peroxide value of SFO, which might be attributed to the decreasing amount of linoleic acids present in the blends. Compared to PV, the $p$-anisidine value $(p-\mathrm{AV})$ is a more reliable and meaningful test, because it measures the secondary oxidation products, which are more stable during the heating process (AL-KAHTANI, 1991). As shown in Table 2, as the number of fryings performed in the oil increased, $p$-AV of the frying oils increased due to decomposition of oil hydroperoxides (NAWAR, 1984). $p$-AVs of SFO were significantly $(\mathrm{P}<0.05)$ different from those of its blends during frying. The SFOs containing 20 and $40 \%$ of $\mathrm{PO}$ underwent the $p$-AV increases (97.94 and 89.77 units, respectively, from the initial); being lower than that of the SFO (111.47 units from the initial). $p$-AV is often used in the industry in conjunction with PV to calculate the so-called total oxidation or TOTOX value given as: TOTOX $=2 \mathrm{PV}+p$-AV (SHAHIDI $\&$ WANASUNDARA, 2002). During the frying process TOTOX values increased significantly $(\mathrm{P}<0.05)$ with frying days (Table 2). The lower TOTOX value of the blends indicated that they are more resistant to oxidative rancidity than the SFO.

As shown in Table 3, the highest reduction (10.64 units from the initial) in the iodine value (IV) was shown by the frying medium SFO, thus indicating that the highest decrease in double bonds occurred due to oxidative rancidity in the proposed frying media. The treatment PSF2 showed the least reduction (8.00 units from the initial) in the IV, thus indicating that less oxidative rancidity occurred in this frying medium. Changes in the ultraviolet absorption at 233 and $269 \mathrm{~nm}\left(\mathrm{E}^{1 \%}{ }_{233}\right.$ and $\left.\mathrm{E}^{1 \%}{ }_{269}\right)$ associated with the changes in the conjugated dienes and trienes, are shown in Table 3. The levels of conjugated dienes and trienes at the end of frying were, however, lowest in PSF2 followed by PSF1, with the highest levels found in SFO. The lower levels of both conjugated dienes and trienes shown in the blends are indications of good oxidative stability of the oil. The viscosity of frying oils increased significantly $(\mathrm{P}<0.05)$ with frying days (Table 3$)$. The viscosity of SFO at day 0 was lower than the blends; afterwards the rate of viscosity for SFO dramatically increased. The present results clearly revealed the higher deteriorative effect of SFO compared to the blends. Polymer content $(\mathrm{PC})$ increased significantly $(\mathrm{P}<0.05)$ with different rates during frying (Table 3). The present results revealed that the frying media SFO showed the highest PC compared to the blends.

The amount of TPCs in the samples increased with the time increment and the rates of increments were significantly different $(\mathrm{P}<0.05)$ from each other (Table 4$)$. The total polar contents of SFO at 5 th day of frying exceeded the limit $27 \%$ for used frying fats based on the German standard (BILLEK et al., 1978). These results indicated that SFO could be used for frying of potato pieces up to day 4, while PSF1 and PSF2 could be used up to day 5 under the frying conditions depicted in the methodology. The SFOs containing 20 and 40\% PO showed no significant differences in their rates of TPC formation at the end of frying; however both exhibited lower rates of TPC formation compared to SFO. When the maximal content for TPC in frying oil is accepted as $27 \%$, the TPC-based stability ranking of these oils would be: PSF2 $>$ PSF1 $>$ SFO. Despite the similar levels of food oil sensor (FOS) values in the fresh oils, the FOS values increased significantly $(\mathrm{P}<0.05)$ with different rates during frying (Table 4$)$. In this case, the highest TPC content and FOS values were both detected in SFO and the lowest ones in PSF2. Table 4 shows changes in the colour of the samples during the 5 days of 
Table 2. Refractive index, free fatty acid, peroxide value, p-anisidine value and TOTOX value of sunflower oil and its blends with palm olein during frying

\begin{tabular}{|c|c|c|c|c|}
\hline \multirow[t]{2}{*}{ Parameter } & \multirow[t]{2}{*}{ Day } & \multirow[t]{2}{*}{ Sunflower oil (SFO) } & \multicolumn{2}{|c|}{ Palm olein:Sunflower oil } \\
\hline & & & 20:80 (PSF1) & 40:60 (PSF2) \\
\hline \multirow{7}{*}{$\begin{array}{l}\text { Refractive index } \\
\left(25^{\circ} \mathrm{C}\right)\end{array}$} & 0 & $1.4724 \pm 0.0004^{\mathrm{cA}}$ & $1.4716 \pm 0.0003^{\mathrm{bA}}$ & $1.4700 \pm 0.0001^{\mathrm{aA}}$ \\
\hline & 1 & $1.4734 \pm 0.0004^{\mathrm{cB}}$ & $1.4718 \pm 0.0004^{\mathrm{bAB}}$ & $1.4703 \pm 0.0002^{\mathrm{aB}}$ \\
\hline & 2 & $1.4736 \pm 0.0003^{\mathrm{cB}}$ & $1.4720 \pm 0.0004^{\mathrm{bABC}}$ & $1.4704 \pm 0.0002^{\mathrm{aB}}$ \\
\hline & 3 & $1.4739 \pm 0.0004^{\mathrm{cB}}$ & $1.4723 \pm 0.0003^{\mathrm{bBCD}}$ & $1.4706 \pm 0.0003^{\mathrm{aB}}$ \\
\hline & 4 & $1.4741 \pm 0.0004^{\mathrm{cB}}$ & $1.4725 \pm 0.0003^{\mathrm{bCD}}$ & $1.4713 \pm 0.0002^{\mathrm{aC}}$ \\
\hline & 5 & $1.4742 \pm 0.0005^{\mathrm{cB}}$ & $1.4730 \pm 0.0001^{\mathrm{bD}}$ & $1.4712 \pm 0.0009^{\mathrm{aD}}$ \\
\hline & 0 & $0.10 \pm 0.00^{\mathrm{aA}}$ & $0.10 \pm 0.01^{\mathrm{aA}}$ & $0.11 \pm 0.01^{\mathrm{aA}}$ \\
\hline \multirow{4}{*}{ Free fatty acid $(\%)$} & 1 & $0.17 \pm 0.01^{\mathrm{aB}}$ & $0.18 \pm 0.00^{\mathrm{aB}}$ & $0.20 \pm 0.03^{\mathrm{aB}}$ \\
\hline & 2 & $0.24 \pm 0.01^{\mathrm{aC}}$ & $0.25 \pm 0.02^{\mathrm{aC}}$ & $0.29 \pm 0.02^{\mathrm{aC}}$ \\
\hline & 3 & $0.28 \pm 0.01^{\mathrm{aD}}$ & $0.30 \pm 0.02^{\mathrm{abD}}$ & $0.33 \pm 0.00^{\mathrm{bD}}$ \\
\hline & 4 & $0.51 \pm 0.02^{\mathrm{aE}}$ & $0.53 \pm 0.02^{\mathrm{aE}}$ & $0.59 \pm 0.01^{\mathrm{bE}}$ \\
\hline \multirow{7}{*}{$\begin{array}{l}\text { Peroxide value } \\
\left(\mathrm{meq} \mathrm{O}_{2} / \mathrm{kg} \text { of oil) }\right.\end{array}$} & 5 & $0.59 \pm 0.03^{\mathrm{aF}}$ & $0.61 \pm 0.01^{\mathrm{aF}}$ & $0.68 \pm 0.01^{\mathrm{bF}}$ \\
\hline & 0 & $1.20 \pm 0.03^{\mathrm{aA}}$ & $1.18 \pm 0.03^{\mathrm{aA}}$ & $1.18 \pm 0.02^{\mathrm{aA}}$ \\
\hline & 1 & $4.08 \pm 0.04^{\mathrm{cB}}$ & $3.80 \pm 0.10^{\mathrm{bB}}$ & $3.56 \pm 0.02^{\mathrm{aB}}$ \\
\hline & 2 & $7.02 \pm 0.08^{\mathrm{cC}}$ & $5.90 \pm 0.04^{\mathrm{bC}}$ & $5.54 \pm 0.08^{\mathrm{aC}}$ \\
\hline & 3 & $9.98 \pm 0.04^{\mathrm{cF}}$ & $9.20 \pm 0.04^{\mathrm{bF}}$ & $9.00 \pm 0.06^{\mathrm{aF}}$ \\
\hline & 4 & $9.20 \pm 0.07^{\mathrm{cE}}$ & $8.67 \pm 0.11^{\mathrm{bE}}$ & $8.20 \pm 0.14^{\mathrm{aE}}$ \\
\hline & 5 & $8.80 \pm 0.31^{\mathrm{bD}}$ & $7.92 \pm 0.10^{\mathrm{aD}}$ & $7.63 \pm 0.09^{\mathrm{aD}}$ \\
\hline \multirow{4}{*}{$p$-anisidine value } & 0 & $2.69 \pm 0.04^{\mathrm{bA}}$ & $2.63 \pm 0.04^{\mathrm{bA}}$ & $2.51 \pm 0.03^{\mathrm{aA}}$ \\
\hline & 1 & $43.90 \pm 0.28^{\mathrm{cB}}$ & $34.27 \pm 0.32^{\mathrm{bB}}$ & $30.12 \pm 0.08^{\mathrm{aB}}$ \\
\hline & 2 & $80.18 \pm 0.56^{\mathrm{cC}}$ & $75.45 \pm 0.45^{\mathrm{bC}}$ & $70.05 \pm 0.41^{\mathrm{aC}}$ \\
\hline & 3 & $99.98 \pm 0.08^{\mathrm{cD}}$ & $89.75 \pm 0.73^{\mathrm{bD}}$ & $81.45 \pm 0.33^{\mathrm{aD}}$ \\
\hline \multirow{8}{*}{ TOTOX value } & 4 & $108.23 \pm 0.65^{\mathrm{cE}}$ & $96.88 \pm 0.63^{\mathrm{bE}}$ & $87.67 \pm 0.14^{\mathrm{aE}}$ \\
\hline & 5 & $114.16 \pm 0.32^{\mathrm{cF}}$ & $100.57 \pm 1.16^{\mathrm{bF}}$ & $92.28 \pm 0.33^{\mathrm{aF}}$ \\
\hline & 0 & $5.09 \pm 0.04^{\mathrm{bA}}$ & $4.99 \pm 0.09^{\mathrm{bA}}$ & $4.87 \pm 0.06^{\mathrm{aA}}$ \\
\hline & 1 & $52.06 \pm 0.28^{\mathrm{cB}}$ & $41.87 \pm 0.41^{\mathrm{bB}}$ & $37.24 \pm 0.13^{\mathrm{aB}}$ \\
\hline & 2 & $94.22 \pm 0.71^{\mathrm{cC}}$ & $87.25 \pm 0.37^{\mathrm{bC}}$ & $81.13 \pm 0.25^{\mathrm{aC}}$ \\
\hline & 3 & $119.94 \pm 0.05^{\mathrm{cD}}$ & $108.16 \pm 0.28^{\mathrm{bD}}$ & $99.45 \pm 0.39^{\mathrm{aD}}$ \\
\hline & 4 & $126.63 \pm 0.80^{\mathrm{cE}}$ & $114.14 \pm 0.52^{\mathrm{bE}}$ & $104.07 \pm 0.40^{\mathrm{aE}}$ \\
\hline & 5 & $131.76 \pm 0.35^{\mathrm{cF}}$ & $116.41 \pm 1.07^{\mathrm{bF}}$ & $107.54 \pm 0.16^{\mathrm{aF}}$ \\
\hline
\end{tabular}

Each value in the table represents the mean of three replicates \pm SD. Values within a row with the same lowercase letters are not significantly different at $\mathrm{P}<0.05$. Values within a column with the same uppercase letters are not significantly different at $\mathrm{P}<0.05$

frying. In most cases, the colour units of all the oils increased significantly $(\mathrm{P}<0.05)$ with the frying days. The PSF2 showed the highest initial red (1.47) and yellow (15.43) colour units; while the SFO showed the least initial magnitude of the red (0.93) and yellow (8.33) colour 
Table 3. Iodine value, viscosity, specific extinction and polymer content of sunflower oil and its blends with palm olein during frying

\begin{tabular}{|c|c|c|c|c|}
\hline \multirow[t]{2}{*}{ Parameter } & \multirow[t]{2}{*}{ Day } & \multirow[t]{2}{*}{ Sunflower oil (SFO) } & \multicolumn{2}{|c|}{ Palm olein:Sunflower oil } \\
\hline & & & 20:80 (PSF1) & 40:60 (PSF2) \\
\hline \multirow{6}{*}{$\begin{array}{l}\text { Iodine value } \\
\text { ( } \mathrm{g} \text { of } \mathrm{I}_{2} / 100 \mathrm{~g} \text { oil) }\end{array}$} & 0 & $130.43 \pm 0.25^{\mathrm{cE}}$ & $115.56 \pm 0.45^{\mathrm{bE}}$ & $102.50 \pm 0.52^{\mathrm{aD}}$ \\
\hline & 1 & $127.00 \pm 1.09^{\mathrm{cD}}$ & $113.29 \pm 0.76^{\mathrm{bD}}$ & $101.98 \pm 0.63^{\mathrm{aD}}$ \\
\hline & 2 & $124.28 \pm 0.38^{\mathrm{cC}}$ & $111.12 \pm 0.51^{\mathrm{bC}}$ & $99.13 \pm 0.67^{\mathrm{aC}}$ \\
\hline & 3 & $122.67 \pm 1.03^{\mathrm{cB}}$ & $110.95 \pm 0.48^{\mathrm{bC}}$ & $97.73 \pm 0.52^{\mathrm{aB}}$ \\
\hline & 4 & $120.11 \pm 0.68^{\mathrm{cA}}$ & $108.33 \pm 0.32^{\mathrm{bB}}$ & $96.62 \pm 0.46^{\mathrm{aB}}$ \\
\hline & 5 & $119.79 \pm 0.97^{\mathrm{cA}}$ & $106.45 \pm 0.80^{\mathrm{bA}}$ & $94.50 \pm 0.76^{\mathrm{aA}}$ \\
\hline \multirow{4}{*}{$\mathrm{E}^{1 \%}{ }_{233}$} & 0 & $1.04 \pm 0.04^{\mathrm{aA}}$ & $1.00 \pm 0.05^{\mathrm{aA}}$ & $0.99 \pm 0.04^{\mathrm{aA}}$ \\
\hline & 1 & $3.02 \pm 0.06^{\mathrm{bB}}$ & $2.55 \pm 0.07^{\mathrm{aB}}$ & $2.40 \pm 0.10^{\mathrm{aB}}$ \\
\hline & 2 & $6.59 \pm 0.04^{\mathrm{cC}}$ & $6.26 \pm 0.06^{\mathrm{bC}}$ & $5.65 \pm 0.02^{\mathrm{aC}}$ \\
\hline & 3 & $8.55 \pm 0.08^{\mathrm{cD}}$ & $7.79 \pm 0.03^{\mathrm{bD}}$ & $7.06 \pm 0.03^{\mathrm{aD}}$ \\
\hline \multirow{8}{*}{$\mathrm{E}^{1 \%}{ }_{269}$} & 4 & $9.55 \pm 0.04^{\mathrm{cE}}$ & $8.23 \pm 0.20^{\mathrm{bE}}$ & $7.75 \pm 0.06^{\mathrm{aE}}$ \\
\hline & 5 & $11.20 \pm 0.31^{\mathrm{cF}}$ & $10.14 \pm 0.10^{\mathrm{bF}}$ & $9.00 \pm 0.24^{\mathrm{aF}}$ \\
\hline & 0 & $0.51 \pm 0.03^{\mathrm{aA}}$ & $0.48 \pm 0.04^{\mathrm{aA}}$ & $0.47 \pm 0.00^{\mathrm{aA}}$ \\
\hline & 1 & $1.55 \pm 0.06^{\mathrm{bB}}$ & $1.41 \pm 0.08^{\mathrm{abB}}$ & $1.35 \pm 0.03^{\mathrm{aB}}$ \\
\hline & 2 & $1.95 \pm 0.05^{\mathrm{cC}}$ & $1.74 \pm 0.04^{\mathrm{bC}}$ & $1.63 \pm 0.06^{\mathrm{aC}}$ \\
\hline & 3 & $2.05 \pm 0.03^{\mathrm{bD}}$ & $1.87 \pm 0.01^{\mathrm{aD}}$ & $1.84 \pm 0.03^{\mathrm{aD}}$ \\
\hline & 4 & $2.65 \pm 0.05^{\mathrm{cE}}$ & $2.41 \pm 0.06^{\mathrm{bE}}$ & $2.14 \pm 0.11^{\mathrm{aE}}$ \\
\hline & 5 & $2.90 \pm 0.02^{\mathrm{cF}}$ & $2.64 \pm 0.15^{\mathrm{bF}}$ & $2.40 \pm 0.03^{\mathrm{aF}}$ \\
\hline \multirow{4}{*}{ Viscosity (cP) } & 0 & $27.23^{ \pm} 0.05^{\mathrm{aA}}$ & $29.56 \pm 0.12^{\mathrm{bA}}$ & $30.27 \pm 0.04^{\mathrm{cA}}$ \\
\hline & 1 & $33.26 \pm 0.04^{\mathrm{aB}}$ & $33.36 \pm 0.04^{\mathrm{aB}}$ & $33.63 \pm 0.05^{\mathrm{bB}}$ \\
\hline & 2 & $35.70 \pm 0.08^{\mathrm{bC}}$ & $35.30 \pm 0.16^{\mathrm{aC}}$ & $35.17 \pm 0.12^{\mathrm{aC}}$ \\
\hline & 3 & $38.26 \pm 0.09^{\mathrm{bD}}$ & $37.93 \pm 0.09^{\mathrm{bD}}$ & $36.26 \pm 0.29^{\mathrm{aD}}$ \\
\hline \multirow{8}{*}{ Polymer content $(\%)$} & 4 & $39.50 \pm 0.08^{\mathrm{cE}}$ & $38.53 \pm 0.04^{\mathrm{bE}}$ & $36.80 \pm 0.08^{\mathrm{aE}}$ \\
\hline & 5 & $42.46 \pm 0.16^{\mathrm{cF}}$ & $39.37 \pm 0.42^{\mathrm{bF}}$ & $37.30 \pm 0.08^{\mathrm{aF}}$ \\
\hline & 0 & $0.70 \pm 0.04^{\mathrm{aA}}$ & $0.66 \pm 0.03^{\mathrm{aA}}$ & $0.64 \pm 0.04^{\mathrm{aA}}$ \\
\hline & 1 & $1.20 \pm 0.05^{\mathrm{bB}}$ & $1.10 \pm 0.05^{\mathrm{abB}}$ & $1.05 \pm 0.08^{\mathrm{aB}}$ \\
\hline & 2 & $1.82 \pm 0.05^{\mathrm{cC}}$ & $1.68 \pm 0.02^{\mathrm{bC}}$ & $1.40 \pm 0.03^{\mathrm{aC}}$ \\
\hline & 3 & $2.48 \pm 0.12^{\mathrm{cD}}$ & $2.13 \pm 0.12^{\mathrm{bD}}$ & $1.60 \pm 0.02^{\mathrm{aD}}$ \\
\hline & 4 & $3.00 \pm 0.12^{\mathrm{bE}}$ & $2.55 \pm 0.02^{\mathrm{aE}}$ & $2.51 \pm 0.12^{\mathrm{aE}}$ \\
\hline & 5 & $3.55 \pm 0.09^{\mathrm{bF}}$ & $3.15 \pm 0.03^{\mathrm{aF}}$ & $3.00 \pm 0.10^{\mathrm{aF}}$ \\
\hline
\end{tabular}

Each value in the table represents the mean of three replicates \pm SD. Values within a row with the same lowercase letters are not significantly different at $\mathrm{P}<0.05$. Values within a column with the same uppercase letters are not significantly different at $\mathrm{P}<0.05$

units; this might be the result of adding PO to SFO. Higher initial values of PO could contribute to the darkness of SFO during frying. CHE MAN and co-workers (1999) reported that blending of soybean oil with palm olein increased the red and yellow units of soybean 
oil. But in the present results, after day 2, yellow colour units in SFO were shown to be higher than those of its blends; this phenomenon could not be explained as before. This might be due to the influence of minor components that led to alter the values or to experimental error. Hence, more rapid development in colour of blends over SFO might not be valid indicator of their stability.

Table 4. Total polar compound, FOS value and colour of sunflower oil and its blends with palm olein during frying

\begin{tabular}{|c|c|c|c|c|}
\hline \multirow[t]{2}{*}{ Parameter } & \multirow[t]{2}{*}{ Day } & \multirow[t]{2}{*}{ Sunflower oil (SFO) } & \multicolumn{2}{|c|}{ Palm olein:Sunflower oil } \\
\hline & & & $20: 80$ (PSF1) & $40: 60$ (PSF2) \\
\hline \multirow{3}{*}{ Total polar compound ( $\%)$} & 0 & $3.12 \pm 0.10^{\mathrm{aA}}$ & $3.65 \pm 0.14^{\mathrm{bA}}$ & $4.30 \pm 0.14^{\mathrm{cA}}$ \\
\hline & 1 & $9.12 \pm 0.09^{\mathrm{aB}}$ & $8.62 \pm 0.45^{\mathrm{aB}}$ & $8.90 \pm 0.29^{\mathrm{aB}}$ \\
\hline & 2 & $17.67 \pm 0.28^{\mathrm{cC}}$ & $15.73 \pm 0.14^{\mathrm{bC}}$ & $15.10 \pm 0.14^{\mathrm{aC}}$ \\
\hline \multirow{10}{*}{ FOS value } & 3 & $20.56 \pm 0.30^{\mathrm{bD}}$ & $19.00 \pm 0.49^{\mathrm{aD}}$ & $18.54 \pm 0.40^{\mathrm{aD}}$ \\
\hline & 4 & $24.58 \pm 0.27^{\mathrm{cE}}$ & $22.12 \pm 0.20^{\mathrm{bE}}$ & $20.10 \pm 0.71^{\mathrm{aE}}$ \\
\hline & 5 & $28.89 \pm 0.78^{\mathrm{bF}}$ & $26.30 \pm 1.02^{\mathrm{aF}}$ & $24.60 \pm 0.35^{\mathrm{aF}}$ \\
\hline & 0 & $1.15 \pm 0.04^{\mathrm{aA}}$ & $1.13 \pm 0.05^{\mathrm{aA}}$ & $1.10 \pm 0.08^{\mathrm{aA}}$ \\
\hline & 1 & $2.15 \pm 0.04^{\mathrm{bB}}$ & $2.00 \pm 0.16^{\mathrm{abB}}$ & $1.80 \pm 0.08^{\mathrm{aB}}$ \\
\hline & 2 & $3.40 \pm 0.08^{\mathrm{cC}}$ & $3.05 \pm 0.12^{\mathrm{bC}}$ & $2.80 \pm 0.08^{\mathrm{aC}}$ \\
\hline & 3 & $3.70 \pm 0.08^{\mathrm{cD}}$ & $3.35 \pm 0.12^{\mathrm{bCD}}$ & $3.06 \pm 0.04^{\mathrm{aC}}$ \\
\hline & 4 & $4.10 \pm 0.08^{\mathrm{bE}}$ & $3.47 \pm 0.08^{\mathrm{aCD}}$ & $3.25 \pm 0.20^{\mathrm{aD}}$ \\
\hline & 5 & $4.20 \pm 0.16^{\mathrm{bF}}$ & $3.70 \pm 0.16^{\mathrm{aD}}$ & $3.53 \pm 0.25^{\mathrm{aD}}$ \\
\hline & 0 & $0.93 \pm 0.09^{\mathrm{aA}}$ & $1.01 \pm 0.08^{\mathrm{aA}}$ & $1.47 \pm 0.05^{\mathrm{bA}}$ \\
\hline \multirow{3}{*}{ Red colour (Lovibond) } & 1 & $1.27 \pm 0.08^{\mathrm{aB}}$ & $1.47 \pm 0.08^{\mathrm{aB}}$ & $2.67 \pm 0.05^{\mathrm{bB}}$ \\
\hline & 2 & $2.23 \pm 0.06^{\mathrm{aC}}$ & $2.53 \pm 0.08^{\mathrm{bC}}$ & $4.70 \pm 0.08^{\mathrm{cC}}$ \\
\hline & 3 & $3.13 \pm 0.08^{\mathrm{bD}}$ & $2.73 \pm 0.05^{\mathrm{aD}}$ & $5.70 \pm 0.08^{\mathrm{cD}}$ \\
\hline \multirow{8}{*}{ Yellow colour (Lovibond) } & 4 & $5.03 \pm 0.05^{\mathrm{bE}}$ & $4.03 \pm 0.05^{\mathrm{aE}}$ & $9.67 \pm 0.05^{\mathrm{cE}}$ \\
\hline & 5 & $5.93 \pm 0.09^{\mathrm{aF}}$ & $6.28 \pm 0.06^{\mathrm{bF}}$ & $10.53 \pm 0.08^{\mathrm{cF}}$ \\
\hline & 0 & $8.33 \pm 0.05^{\mathrm{aA}}$ & $9.73 \pm 0.05^{\mathrm{bA}}$ & $15.43 \pm 0.05^{\mathrm{cA}}$ \\
\hline & 1 & $10.63 \pm 0.08^{\mathrm{aB}}$ & $10.83 \pm 0.12^{\mathrm{aB}}$ & $20.67 \pm 0.05^{\text {bB }}$ \\
\hline & 2 & $19.30 \pm 0.08^{\mathrm{aC}}$ & $20.77 \pm 0.12^{\mathrm{bC}}$ & $20.83 \pm 0.12^{\mathrm{bB}}$ \\
\hline & 3 & $32.57 \pm 0.09^{\mathrm{bD}}$ & $20.73 \pm 0.12^{\mathrm{aC}}$ & $20.63 \pm 0.19^{\mathrm{aB}}$ \\
\hline & 4 & $48.63 \pm 0.19^{\mathrm{cE}}$ & $29.17 \pm 0.12^{\mathrm{aD}}$ & $30.03 \pm 0.05^{\mathrm{bC}}$ \\
\hline & 5 & $54.60 \pm 0.14^{\mathrm{cF}}$ & $38.67 \pm 0.05^{\mathrm{aE}}$ & $39.67 \pm 0.12^{\mathrm{bD}}$ \\
\hline
\end{tabular}

Each value in the table represents the mean of three replicates \pm SD. Values within a row with the same lowercase letters are not significantly different at $\mathrm{P}<0.05$. Values within a column with the same uppercase letters are not significantly different at $\mathrm{P}<0.05$.

\section{Conclusion}

In this study, most of the chemical and physical degradation indicators suggested that the degradation was the fastest in SFO as compared to its blends with PO. Overall, based on the 
results reported herein, it can be concluded that addition of PO to SFO slowed down the thermooxidative degradation rate of the SFO and in this regard, PSF2 showed better performance than PSF1. However, some degradation indicators, such as free fatty acid content and colour, increased faster in the blends compared to SFO. Therefore, further research is needed to find additional factors that are responsible to enhance the level of such indicators in the blends.

Authors gratefully acknowledge the financial support received under the Short Term Research Grant of the Universiti Teknologi Malaysia.

\section{References}

Al-Kahtani, H. (1991): Survey of quality of used frying oils from restaurants. J. Am. Oil Chem. Soc., 68, 857-862.

A.O.C.S. (1987): Official methods and recommended practices of the American Oil Chemists' Society. (4 ${ }^{\text {th }}$ ed) A.O.C.S. press, Champaign. Refractive index (method Cc 7-25); free fatty acid content (method Ca 5a-40); iodine value (method Cd 1b-87); peroxide value (method $\mathrm{Cd} 8-53$ ).

Billek, G., Guhr, G. \& Waibel, J. (1978): Quality assessment of used frying fats: A comparison of four methods. $J$. Am. Oil Chem. Soc., 55, 728-732.

Che Man, Y.B., Liu, J.L., Jamilah, B. \& Rahman, R.A. (1999): Quality changes of refined-bleached-deodorized (RBD) palm olein, soybean oil and their blends during deep-fat frying. J. Fd Lipids, 6, 181-193.

Chu, Y.H. \& Kung, Y.L. (1998): A study on vegetable oil blends. Fd Chem., 62, 191-195.

De Marco, E., Savarese, M., Parisini, C., Battimo, I., Falco, S. \& Sacchi, R. (2007): Frying performance of a sunflower/palm oil blend in comparison with pure palm oil. Eur. J. Lipid Sci. Technol., 109, 237-246.

Dobarganes, M.C., Velasco, J. \& Dieffenbacher, A. (2000): Determination of polar compounds, polymerized and oxidized triacylglycerols and diacylglycerols in oils and fats. Pure Appl. Chem., 72, 1563-1575.

Enríquez-Fernández, B.E., Álvarez De La, C.Y.Y.L., \& Sosa-Morales, M.E. (2011): Comparison of the stability of palm olein and a palm olein/canola oil blend during deep-fat frying of chicken nuggets and French fries. Int. J. Fd Sci. Technol., 46, 1231-1237.

Huang, A.S., Hsieh, O.A.L., Huang, C.L. \& Chang, S.S. (1981): A comparison of the stability of sunflower oil and corn oil. J. Am. Oil Chem. Soc., 58, 997-1001.

LabuZA, T.P. (1971): Kinetics of lipid oxidation in foods. CRC Crit. Rev. Fd Technol., 2, 355-404.

Matthaus, B. (2006): Utilization of high-oleic rapeseed oil for deep fat frying of French fries compared to other commonly used edible oils. Eur. J. Lipid Sci. Technol., 108, 200-211.

NAWAR, W.W. (1984): Chemical changes in lipids produced by thermal processing. J. Am. Oil Chem. Soc., 61, 299302.

Normand, L., Eskin, N.A.M. \& Przybylski, R. (2001): Effects of tocopherols on the frying stability of regular and modified canola oils. J. Am. Oil Chem. Soc., 78, 369-373.

Peled, M., Gutfinger, T. \& Letan, A. (1975): Effect of water and BHT on stability of cottonseed oil during frying. J. Sci. Fd Agric., 26, 1655-1666.

PORIM (1995): PORIM Test Methods. Palm Oil Research Institute of Malaysia, Ministry of Primary Industries, Malaysia. Determination of specific extinctions (method p2.15); $p$-anisidine value (method p2.4); colour: (method p4.1).

Sanibal, E.A.A. \& Mancini-Filho, J. (2004): Frying oil and fat quality measured by chemical, physical, and test kit analyses. J. Am. Oil Chem. Soc., 81, 847-852.

Shahidi, F. \& Wanasundara, U.N. (2002): Methods for measuring oxidative rancidity in fats and oils. -in: AKoH, C.C. \& Min, D.B. (Eds.) Food lipids: Chemistry, nutrition, and biotechnology. (2 ${ }^{\text {nd }}$ ed.) Marcel Dekker, Inc., New York, pp. 465-482.

TEAH, Y.K. (1988): Improvements in the frying quality of vegetable oils by blending with palm olein. -in: Palm Oil Developments, Malaysian Palm Oil Board, Kuala Lumpur, pp. 1-4. 